\title{
Achieving JIT procurement of small nuclear power manufacturing enterprises
}

\author{
Min $\mathrm{Fu}^{\mathrm{a},{ }^{*}}$, Fengchao Yang ${ }^{\mathrm{b}}$ and Xue $\mathrm{Li}^{\mathrm{c}}$ \\ China Nuclear Power Technology Research Institute Beijing Division \\ FL. 11th, CEC Building, No.6 south zhong guan cun St., Haidian District, Beijing, P.R.China \\ afu-min@cgnpc.com.cn, \\ byangfengchao@cgnpc.com.cn, \\ clixue@cgnpc.com.cn \\ *Corresponding author
}

Keywords: punctual strategy, order driven, just in time, procurement production.

\begin{abstract}
This paper combines the physical truth of nuclear power manufacturing enterprises, introduces the concept of just-in-time strategy, proposes an procurement method of order-driven in the premise of meeting the requirements and the normal operation of nuclear power enterprises 。

By designing various tools suitable for enterprises, classifying the materials according to the actual purchasing characteristics of enterprises, and managing the corresponding suppliers. It makes the enterprises achieve seamless connection and automatic operation from purchasing to production, achieving the purpose of punctual purchasing and production of small and medium-sized nuclear power enterprises.
\end{abstract}

\section{Introduction}

Nuclear power plants must adhere to the principle of "safety first, quality first" at all times. Safety is the commander, quality is the guarantee. Purchasing work is an important part of nuclear power plant works. Purchasing quality affects the quality of purchasing goods and services, and the quality of purchasing goods and services affects the quality of nuclear power plant operation.

JIT (Just in time) is the abbreviation for punctual strategy. Just-in-time purchasing is a kind of more advanced management mode, and it is also a kind of purchasing mode facing customer's demand directly. The basic concept of just-in-time purchasing is to provide the right goods with the right quantity and quality at the right time and place ${ }^{[1]}$. Good implementation of on-time purchasing can meet the needs of users and achieve the purpose of cost reduction and efficiency better while reducing inventory pressure.

\section{The Status And Characteristics of Nuclear Power Manufacturing Enterprises}

Nuclear power manufacturing enterprises have stricter requirements for material quality, cumbersome purchasing process, and the materials needed for product production are independently undertaken by the purchasing department. Coordination and communication between R \& D (research and development design), purchasing, manufacturing departments and suppliers are not smooth. Everyone concentrates on the business operation within the scope of this department, not on the business operation. Everyone concentrates on the operation of the business within the scope of the department, not on the overall production organization of the enterprise, resulting in high costs and a lack of competitiveness of the product. Most enterprises have paid high prices for supply chain related systems such as ECP system, ERP system ,MDM public data coding platform. However, due to the limitations of cost, scope of application, etc., they can only operate part of the company's departments and individuals'rights to open, and can not benefit the suppliers, departments and owners of the enterprise supply chain. All roles can't achieve complete sharing of information. 


\section{Research on the Realization of JIT Purchasing in Nuclear Power Manufacturing Enterprises}

\subsection{Overall Design}

Just In Time (JIT) is an order driven purchasing mode. If a nuclear power manufacturing enterprise wants to realize just-in-time purchasing, it should first analyze the characteristics of purchasing items and classify them so as to find the most suitable supplier for different types of items. Then, it should select or design the suitable IT software for the company to use. Finally, after the design of just-in-time purchasing model is completed. Carry out the pilot work from the point to the surface.

Figure 1 is a chart showing the JIT purchasing process of order driving mode. If every link in the process can run smoothly and quickly, the information sharing and supplier classification and selection play a key role ${ }^{[2]}$.

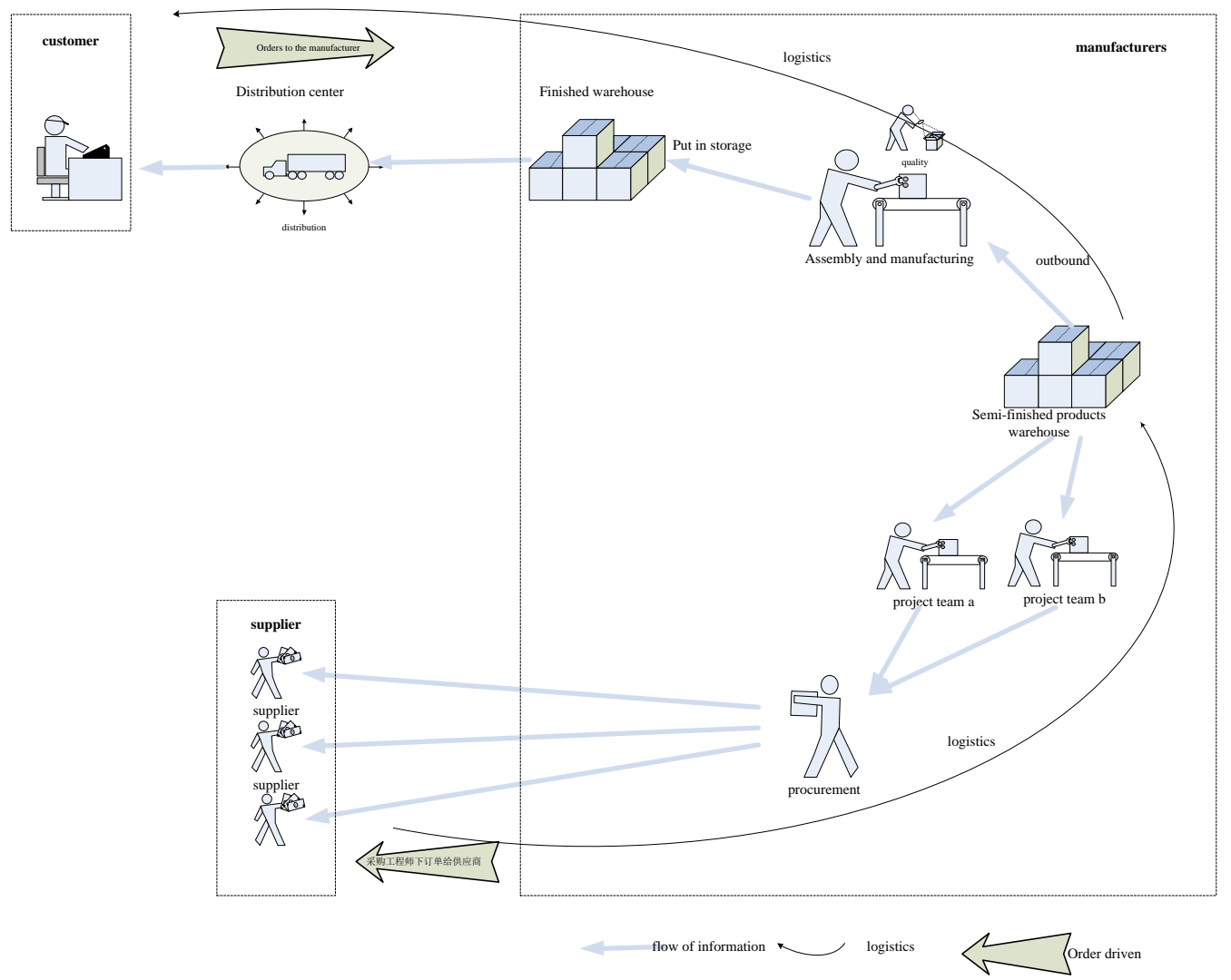

Figure 1 JIT purchasing process of order driving mode

\subsection{Supplementary Design of Information Sharing Tools}

Informationization is the foundation of enterprise purchasing business. Optimizing enterprise purchasing mode, improving the responsiveness to user needs, improving the coordination between management departments and improving the rationality of resource allocation. JIT purchasing requires a high degree of sharing of demand information between suppliers and buyers, and also to ensure the accuracy and real-time of this information, even if problems can be found and dealt with in a timely manner.

JIT purchasing is order-driven, which requires enterprises to have the ability to aggregate and share information among departments within the order-driven enterprise. Large enterprises buy large software platforms such as ERP and MDM to solve the problem of information sharing. It is not uncommon for small and medium-sized enterprises limited by the scope of funds and use of large software platforms. 
According to the inapplicability of large-scale software, the author uses VBA programming method to produce a variety of materials checking tools, payment tools, production tools, manual checking program to achieve, eliminating a variety of non-value-added activities of human work. Table 1 is showing the data comparison before and after using tools the optimization.

Table 1. data comparison before and after using tools the optimization

\begin{tabular}{|c|c|c|c|c|c|}
\hline number & part & $\begin{array}{l}\text { before } \\
\text { optimizing }\end{array}$ & $\begin{array}{l}\text { after } \\
\text { optimizing }\end{array}$ & $\begin{array}{l}\text { Optimization } \\
\text { rate }\end{array}$ & Tool design \\
\hline 1 & $\begin{array}{l}\text { contract orders } \\
\text { production of } \\
\text { batch devices }\end{array}$ & 30 (days) & 11 (days) & $63 \%$ & $\begin{array}{l}\text { Designing tools which can } \\
\text { achieve automatic check of } \\
\text { different purchasing items } \\
\text { and information in five documents. }\end{array}$ \\
\hline 2 & Payment & $60(\min )$ & $15(\min )$ & $75 \%$ & $\begin{array}{l}\text { Designing tools which can } \\
\text { achieve automatic check of } \\
\text { different The supplier's invoice } \\
\text { and godown entry information }\end{array}$ \\
\hline 3 & Production & $5(h)$ & 1 (h) & $80 \%$ & $\begin{array}{l}\text { Designing tools which can achieve } \\
\text { making The administrator accurately } \\
\text { locate the location of each } \\
\text { material,arrival notice.That can } \\
\text { provide a basis for punctual } \\
\text { production. }\end{array}$ \\
\hline 4 & $\begin{array}{l}\text { Error rate } \\
\text { comparison of } \\
\text { list register }\end{array}$ & $3 \%$ & 0 & $100 \%$ & $\begin{array}{l}\text { Designing items which can provide } \\
\text { purchasing information without error, } \\
\text { track unqualified products, increase } \\
\text { information posting. }\end{array}$ \\
\hline 5 & $\begin{array}{l}\text { Delayed } \\
\text { purchase rate }\end{array}$ & $5 \%$ & $2 \%$ & $60 \%$ & $\begin{array}{l}\text { Designing items which can } \\
\text { transfer purchasing information } \\
\text { without error,translate and share } \\
\text { the time information into } \\
\text { materials location, arrival information, } \\
\text { early warning. }\end{array}$ \\
\hline
\end{tabular}

\subsection{Material classification and supplier management}

From purchasing material classification to supplier classification is method of systematic strategic procurement, such as production

Companies can distinguish material into the core material, bottlenecks material , lever material and conventional material, and according to the characteristics of the material, different degree of impact on corporate profits to determine factors of supplier selection, to determine the appropriate suppliers.

\subsection{JIT procurement implementation method}

Nuclear power enterprises can start from a certain product, a certain production line or a certain material, according to production plan to choose the long-term cooperation supplier of quality assured, to begin the JIT procurement,

In the process of the test, the need to support and cooperate with the enterprise relevant departments, especially the production department. Nuclear power enterprises can through the production management system, Make better supplies department master production plan and schedule, to ensure the overall success of the JIT procurement ${ }^{[3]}$.

Finally on the basis of the test, gradually expanding the scope of the JIT procurement to be successful. 


\section{Summary}

JIT procurement is advanced mode of enterprise procurement management, is a process of constantly improve and improve, need to constantly monitor

in the implementation process, find out the root of the problem,

Improvements to lower transport costs, provide delivery accuracy, improve product quality, reduce the supply of inventory, and other aspects to improve, and constantly improve the operation performances of JIT purchasing, from the basic work, create conditions and gradually achieve, the effect of yield twice the result with half the effort, create economic benefits for enterprises and improve the competition ability of enterprise.

\section{References}

[1] Fengmin Shan. application of JIT procurement Based on Supply Chain in Manufacturing Companies [J]. Logistics Engineering and Management, 2014, 5 : 136-137

[2] A Gunasekaran,P Ccecille.Experiences of a Small Company in Productivity Improvements.Production and Inventory Management Journal Second Quarter,1998.49-54

[3] O Kermit Hobbs,Jr.Managingl JIT Toward Maturity.Production and Inventory Management Journal First Quarter,1997.47-50.2 